\title{
Characteristics and comearch Paper Characteristics and comparison between diabetes mellitus and non-diabetes mellitus among chronic kidney disease patients: A cross-sectional study of the Chinese Cohort Study of Chronic Kidney Disease (C-STRIDE)
}

\author{
Jun-Jun Zhang ${ }^{1,2, *}$, Liu Yang ${ }^{1,2, *}$, Jun-Wen Huang ${ }^{1,2}$, Yu-Jie Liu ${ }^{3}$, Jin-Wei Wang ${ }^{4}$, \\ Lu-Xia Zhang ${ }^{4}$, Ming-Hui Zhao ${ }^{4}$ and Zhang-Suo Liu ${ }^{1,2}$ \\ ${ }^{1}$ Department of Nephrology, The First Affiliated Hospital of Zhengzhou University, Zhengzhou, Henan, China \\ ${ }^{2}$ Research Institute of Nephropathy, Zhengzhou University, Zhengzhou, Henan, China \\ ${ }^{3}$ Department of Nephrology and Rheumatology, Children's Hospital of Zhengzhou City, Zhengzhou, Henan, China \\ ${ }^{4}$ Renal Division, Department of Medicine, Peking University First Hospital, Beijing, China \\ "These authors contributed equally to this work \\ Correspondence to: Zhang-Suo Liv, email: zhangsuoliv@sina.com
}

Keywords: chronic kidney disease; diabetes mellitus; clinical traits; medication; diabetic nephropathy

Received: March 02, $2017 \quad$ Accepted: October 13, $2017 \quad$ Published: November 18, 2017

Copyright: Zhang et al. This is an open-access article distributed under the terms of the Creative Commons Attribution License 3.0 (CC BY 3.0), which permits unrestricted use, distribution, and reproduction in any medium, provided the original author and source are credited.

\section{ABSTRACT}

Although the prevalence of chronic kidney disease (CKD) and diabetes mellitus (DM) is increasing globally, information on Chinese CKD patients with DM is lacking. A total of 3499 pre-dialysis CKD patients from across China were enrolled in the Chinese Cohort Study of Chronic Kidney Disease (C-STRIDE) between November 2011 and April 2016. We divided the C-STRIDE patients into CKD with DM and CKD without DM groups and compared their clinical, demographic, and laboratory data in this crosssectional study. CKD patients with DM were older, had a higher male-to-female ratio, and had more complications than CKD patients without DM. Age, smoking, and 24-h urinary protein levels were associated with co-occurrence of CKD and DM. Less than $\mathbf{5 0} \%$ of patients in either group took antilipemic, cardiovascular, cerebrovascular, or anti-anemic drugs. In addition, only $18.38 \%$ of CKD patients with DM had undergone a renal biopsy, and diabetic nephropathy was confirmed in $35.4 \%$ of them. Our findings suggest that several types of medication and renal biopsies should be used more frequently in the treatment of Chinese CKD patients with DM.

\section{INTRODUCTION}

Incidences of diabetes mellitus (DM) have increased rapidly around the world because of changes in human environments, behaviors, and lifestyles [1-3]. The International Diabetes Federation Diabetes Atlas (7th edition) reports that 415 million people suffered from DM in 2015. By 2040, an estimated 642 million people will have DM globally, which equates to approximately 1 in 10 adults. In mainland China, 109.6 million adults have DM; China had more adults with DM than any other countries or territories in the world in 2015 [1]. In addition, an estimated 119.5 million people in China have chronic kidney disease (CKD) $[4,5]$, and at least 24.3 million
Chinese CKD patients also have DM [6]. When a patient has both CKD and DM, the two diseases aggravate each other and result in particularly difficult-to-treat clinical manifestations. However, the clinical and pathological characteristics of Chinese patients with both CKD and DM remain unclear. Here, we collected and analyzed data from an established national pre-dialysis CKD patient cohort, the Chinese Cohort Study of Chronic Kidney Disease (C-STRIDE) [7]. We examined demographic details, clinical characteristics, complications, concomitant medication, and histopathological diagnosis of patients with both CKD and DM compared to patients with CKD alone in an effort to identify the most effective clinical treatment strategies. 


\section{RESULTS}

\section{Demographic, clinical, and laboratory characteristics of CKD patients with and without DM}

A total of 3499 pre-dialysis CKD patients were included in the study, of which 2066 were males $(59.05 \%)$ and 1433 were females $(40.95 \%)$ (Table 1). Of these patients, 635 also had DM (CKD with DM, 18.14\%) while 2864 did not have DM (CKD without DM, 81.86\%).

Male-to-female ratio and mean age were higher in the CKD with DM group. In addition, a larger proportion of CKD patients with DM were smokers $(48.86 \%)$ compared to CKD patients without DM $(36.22 \%$, $P<0.001)$. Percentages of patients who used alcohol did not differ between the groups. CKD patients with DM were generally less well-educated.

CKD patients with DM had more severe kidney disease as indicated by CKD stages (Table 1). Systolic blood pressure was also higher in CKD patients with DM than in those without DM $(P<0.001)$. Diastolic blood pressure was similar in both groups. Mean BMI was higher in CKD patients with DM $(25.44 \pm 3.39)$ than in those without DM $(24.29 \pm 3.64, P<0.001)$. CKD patients with DM were also more likely to have a history of hypertension, myocardial infarction, arrhythmia, cerebrovascular disease, and peripheral artery disease $(P<0.005)$.

The main laboratory findings are shown in Table 1. Notably, laboratory data suggested that CKD patients with DM had more complicated and severe disease in many ways. Fasting glucose, 24-h urinary protein, serum creatinine, alkaline phosphatase, and triglyceride levels were higher in CKD patients with DM than in those without DM $(P<0.001)$. Hemoglobin, total protein, serum albumin, and high-density lipoprotein cholesterol levels were lower in CKD patients with DM than in those without DM $(P<0.001)$. Total cholesterol was lower in CKD patients with DM than in those without DM $(P<0.05)$.

Based on standard definitions, we found that higher percentages of CKD patients with DM had hypertension, hyperlipidemia, anemia, hypoalbuminemia, and vascular disease compared to those without DM $(P<0.001)$ (Figure 1A).

When administration of therapeutic drugs was examined, less than $50 \%$ of patients in both groups received antilipemic drugs, cardiovascular drugs, cerebrovascular drugs, and antianemic drugs; only antihypertensive drugs were administered to more than $50 \%$ of patients. Although anemia was more common in CKD patients with DM, they received antianemic drugs less often than CKD patients without DM $(P<0.001)$ (Figure 1B).

\section{Logistic regression analysis of factors related to CKD with and without DM}

Multivariable logistic regression analysis revealed that age, 24-h urinary protein, alkaline phosphatase, CKD$3 \mathrm{a}$ and CKD-3b stages, BMI, hypoalbuminemia, anemia, hypertension, smoking, and vascular disease history were positively associated with CKD with DM. However, level of education, C-reactive protein, and hyperuricemia were negatively associated with CKD with DM. Gender, CKD-2 and CKD-4 stages, hyperlipidemia, malignant tumor, urologic surgical procedures, frequency of alcohol use, and total protein were not associated with CKD with DM (Table 2).

\section{Renal biopsy and pathological characteristics of CKD patients with and without DM}

Of the 635 CKD patients with DM, 111 underwent renal biopsies (18.38\%), while 1180 (42.91\%) of the 2864 CKD patients without DM underwent a renal biopsies; this difference was significant $(P<0.001)$. Renal biopsy reports were available for 99 CKD patients with DM (Table 4). Thirty-five (35.4\%) of these patients were diagnosed with diabetic nephropathy and two (2.0\%) were diagnosed with diabetic nephropathy with IgA nephropathy (IgAN); together, these patients accounted for $37.4 \%$ of all CKD patients with DM patients who underwent renal biopsies. Of the remaining CKD patients with DM who underwent biopsies, 20 (20.2\%) had IgAN, $17(17.2 \%)$ had membranous nephropathy (MN), and $9(9.1 \%)$ had mesangial proliferative glomerulonephritis. In CKD patients without DM, IgAN was the most common disease type (48.93\%), followed by MN (14.36\%).

\section{DISCUSSION}

DM is a leading cause of CKD, and approximately $20-30 \%$ of patients with type II DM suffer from moderate to severe impairments of renal function. An estimated 21.3\% of DM patients in Chinese urban areas have CKD [5]. About $30 \%$ of American adults with DM have elevated spot urine albumin excretion readings of over $30 \mathrm{mg} / \mathrm{g}$ creatinine, and $19.3 \%$ have eGFRs below $60 \mathrm{~mL} / \mathrm{min} / 1.73 \mathrm{~m}^{2}$ [8]. The clinicopathological characteristics of CKD patients with DM are even more complicated.

Here, we examined clinical data from the largest existing cohort of Chinese CKD patients. We found that the incidence of anemia was higher in CKD patients with DM than in patients with CKD alone. Similar results have been reported in other studies [9-11]. This higher incidence of anemia in CKD patients with DM might be associated with urinary albumin excretion, chronic inflammation, glomerular 
Table 1: Demographic, clinical, and laboratory features of CKD patients with and without DM

\begin{tabular}{|c|c|c|c|c|}
\hline & $\begin{array}{l}\text { CKD with DM group } \\
\qquad(n=635)\end{array}$ & $\begin{array}{l}\text { CKD without DM } \\
\text { group }(n=2864)\end{array}$ & $P$ value & Missing number \\
\hline Age & & & & 0 \\
\hline Mean age & $56.93 \pm 10.42$ & $46.20 \pm 13.46$ & $<0.001^{*}$ & \\
\hline $18-44$ years & $83(13.07 \%)$ & $1347(47.10 \%)$ & $<0.001^{*}$ & \\
\hline $45-59$ years & $261(41.10 \%)$ & $961(33.60 \%)$ & & \\
\hline$\geq 60$ years & $291(45.83 \%)$ & $552(19.30 \%)$ & & \\
\hline Gender & & & $<0.001^{*}$ & 0 \\
\hline Male & $412(64.88 \%)$ & $1654(57.75 \%)$ & & \\
\hline Female & $223(35.12 \%)$ & $1210(42.25 \%)$ & & \\
\hline Education completed & & & $<0.001^{*}$ & 35 \\
\hline Junior high school or less & $348(55.59 \%)$ & $1197(42.18 \%)$ & & \\
\hline Senior high school and above & $278(44.41 \%)$ & $1641(57.82 \%)$ & & \\
\hline BMI & $25.44 \pm 3.39$ & $24.29 \pm 3.64$ & $<0.001^{*}$ & 329 \\
\hline Systolic pressure (mmHg) & $137.86 \pm 18.19$ & $127.65 \pm 16.81$ & $<0.001^{*}$ & 443 \\
\hline Diastolic pressure (mmHg) & $80.72 \pm 10.53$ & $81.08 \pm 11.83$ & 0.85 & 443 \\
\hline CKD stage & & & $<0.001^{*}$ & 294 \\
\hline CKD 1 & $31(5.35 \%)$ & $418(15.92 \%)$ & & \\
\hline CKD 2 & $48(8.29 \%)$ & $483(18.39 \%)$ & & \\
\hline CKD 3a & $110(19.00 \%)$ & $392(14.93 \%)$ & & \\
\hline CKD 3b & $180(31.09 \%)$ & $601(22.89 \%)$ & & \\
\hline CKD 4 & $210(36.27 \%)$ & $732(27.88 \%)$ & & \\
\hline Smoking history & & & $<0.001^{*}$ & 110 \\
\hline Yes & $300(48.86 \%)$ & $1005(36.22 \%)$ & & \\
\hline $\begin{array}{l}\text { Frequency of alcohol use in } \\
\text { past year }\end{array}$ & & & 0.13 & 136 \\
\hline Never & $499(81.67 \%)$ & $2151(78.16 \%)$ & & \\
\hline Occasionally & $84(13.75 \%)$ & $467(16.97 \%)$ & & \\
\hline Frequently & $28(4.58 \%)$ & $134(4.87 \%)$ & & \\
\hline \multicolumn{5}{|l|}{ Previous medical illness } \\
\hline Hypertension & $515(81.10 \%)$ & $1728(61.10 \%)$ & $<0.001^{*}$ & 36 \\
\hline Myocardial infarction & $23(3.62 \%)$ & $49(1.73 \%)$ & $0.003^{*}$ & 36 \\
\hline Congestive heart failure & $10(1.58 \%)$ & $22(0.78 \%)$ & 0.06 & 41 \\
\hline Arrhythmia & $42(6.64 \%)$ & $96(3.39 \%)$ & $<0.001^{*}$ & 38 \\
\hline Cerebrovascular disease & $91(14.40 \%)$ & $150(5.31 \%)$ & $<0.001^{*}$ & 40 \\
\hline Peripheral arterial disease & $29(4.59 \%)$ & $24(0.85 \%)$ & $<0.001^{*}$ & 39 \\
\hline Malignant tumor & $7(1.11 \%)$ & $27(0.95 \%)$ & 0.72 & 39 \\
\hline Urologicsurgical procedures & $26(4.15 \%)$ & $98(3.50 \%)$ & 0.43 & 72 \\
\hline \multicolumn{5}{|l|}{ Laboratory features } \\
\hline 24-hour urinary protein $(\mathrm{g} / 24 \mathrm{~h})$ & $1.87(0.60,4.55)$ & $0.84(0.31,1.97)$ & $<0.001^{*}$ & 589 \\
\hline C-reactive protein $(\mathrm{mg} / \mathrm{L})$ & $1.43(0.54,3.46)$ & $1.31(0.52,3.18)$ & 0.22 & 662 \\
\hline Hemoglobin (g/L) & $118.63 \pm 22.70$ & $146.20 \pm 13.46$ & $<0.001^{*}$ & 381 \\
\hline Total protein $(\mathrm{g} / \mathrm{L})$ & $51.25 \pm 26.71$ & $56.76 \pm 25.27$ & $<0.001^{*}$ & 438 \\
\hline Serum albumin $(\mathrm{g} / \mathrm{L})$ & $36.19 \pm 7.85$ & $39.22 \pm 6.62$ & $<0.001^{*}$ & 481 \\
\hline
\end{tabular}


Alkaline phosphatase $(\mu / \mathrm{L})$

Serum creatinine $(\mu \mathrm{M})$

Blood uric acid $(\mu \mathrm{M})$

Total cholesterol (mM)

Triglyceride (mM)

Fasting glucose (mM)

Low density lipoprotein (mM)

High density lipoprotein (mM)

$$
72(56,88)
$$

$157.9(126,218)$

$403.48 \pm 106.49$

$4.68(3.8,5.9)$

$1.86(1.35,2.67)$

$6.17(5.05,7.61)$

$2.56(2.06,3.32)$

$1.03(0.85,1.26)$

$$
\begin{gathered}
64(52,80) \\
142(98,204) \\
406.42 \pm 121.86 \\
4.76(3.94,5.8) \\
1.77(1.24,2.59) \\
4.83(4.38,5.32) \\
2.57(2.05,3.21) \\
1.08(0.9,1.32)
\end{gathered}
$$

$\begin{array}{cc}<0.001^{*} & 492 \\ <0.001^{*} & 294 \\ 0.42 & 336 \\ 0.02^{*} & 478 \\ <0.001^{*} & 480 \\ <0.001^{*} & 507 \\ 0.46 & 528 \\ <0.001^{*} & 528\end{array}$

${ }^{*} P<0.05$. BMI: Body Mass Index, CKD: Chronic Kidney Disease.

hyperfiltration, oxidative stress, use of angiotensin-converting enzyme inhibitors/angiotensin receptor blockers, loss of peritubular capillaries, up regulation of the local reninangiotensin system, effects of autonomic neuropathy, and microvascular damage [12-16].

The incidence of hyperlipidemia was also higher in CKD patients with DM than in those without DM, which is in agreement with a previous finding that dyslipidemia was common, and a major risk factor for cardiovascular complications, in CKD patients with DM [17]. Chronic hyperglycemia in DM patients might contribute to many common endothelial injuries. In addition, reduced lipoprotein lipase activity might increase triglyceride and low-density lipoprotein cholesterol levels, and reduce highdensity lipoprotein cholesterol levels, in DM patients [18]. Hypoalbuminemia was more common in CKD patients with DM than in those without DM as well, possibly due to increased urinary albumin excretion in patients with both $\mathrm{CKD}$ and DM that can lead to serum albumin leakage.

Both systolic blood pressure and the percentage of patients with hypertension-related complications were higher in CKD patients with DM than in those without DM, which was consistent with a study of Japanese patients [19]. Increased blood volume and vascular resistance resulting from insulin resistance in DM might contribute to the development of hypertension [20]. In patients with both DM and $\mathrm{CKD}$, additional factors, such as sympathetic stimulation, renin-angiotensin-aldosterone system activation, watersodium retention, and reductions in levels of vasoactive substances, may contribute to elevated blood pressure [21].

In this study, patients with both CKD and DM had a higher incidence of cardiovascular disease than CKD patients without DM, which is consistent with a previous study [22]. Hypertension and dyslipidemia might contribute to cardiovascular disease in CKD patients with DM. Additionally, chronic inflammation, insulin resistance, endothelial dysfunction, and atherogenic lipoprotein variation play important roles in the development of cardiovascular complications [23].

In our analysis of factors that might be associated with co-occurrence of CKD and DM, age, anemia, hypoproteinemia, hypertension, cardiovascular disease, smoking, BMI, and 24-h urinary protein level were identified as possible contributors. However, these factors cannot be confirmed as risk factors for diabetic kidney disease due to limitations of the cross-sectional design used in this study. Previous studies have suggested that age, smoking, BMI, and proteinuria are risk factors for the

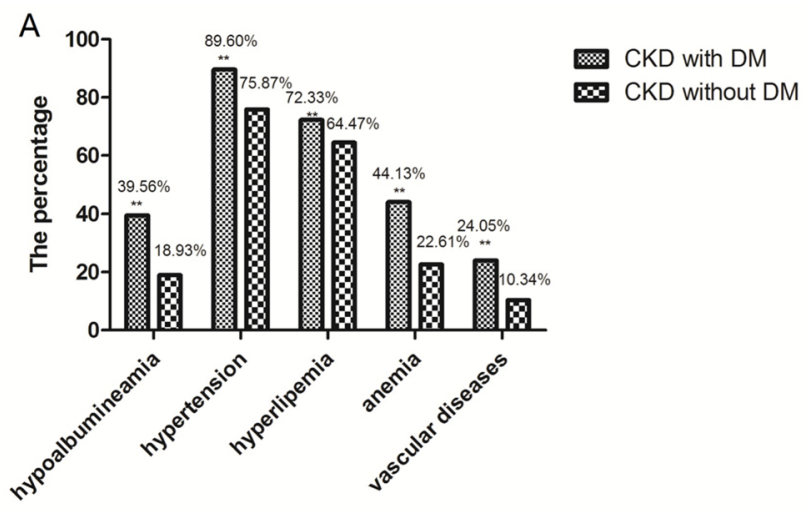

Prevalence of complications in chronic kidney disease (CKD) patients

with and without diabetes mellitus $(\mathrm{DM})(* * P<0.001)$.
B

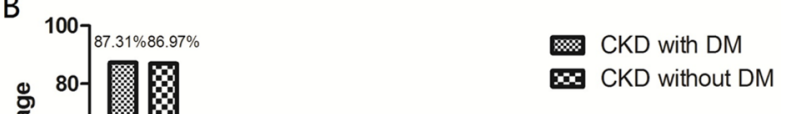

Figure 1: (A) Prevalence of complications in chronic kidney disease (CKD) patients with and without diabetes mellitus (DM) $\left({ }^{* *} P<0.001\right)$. (B) Treatments administered for complications in chronic kidney disease (CKD) patients with and without diabetes mellitus $(\mathrm{DM})\left({ }^{* *} P<0.001\right)$. 
Table 2: Variable assignment table

\begin{tabular}{|c|c|c|c|c|c|}
\hline \multirow{2}{*}{$\frac{\text { Variable }}{\text { CKD Patients }(\mathrm{Y})}$} & \multicolumn{5}{|c|}{ Assignment } \\
\hline & $\begin{array}{l}\text { CKD without } \\
\mathrm{DM}=0\end{array}$ & $\begin{array}{l}\text { CKD with } \\
\mathrm{DM}=1\end{array}$ & & & \\
\hline Gender (X1) & Male $=0$ & Female $=1$ & & & \\
\hline Age (X2) & $18-44=0$ & $45-59=1$ & $\geq 60=2$ & & \\
\hline Education completed (X3) & $\begin{array}{l}\text { Junior high } \\
\text { school or } \\
\text { less }=0\end{array}$ & $\begin{array}{l}\text { Senior high } \\
\text { school and } \\
\text { above }=1\end{array}$ & & & \\
\hline 24 h UP (X4) & $\begin{array}{c}24 \text { h UP }<1 \\
=0\end{array}$ & $\begin{array}{c}1<24 \mathrm{~h} \mathrm{UP}< \\
\quad 3.5=1\end{array}$ & $\begin{aligned} 3.5 & <24 \text { h UP } \\
& <6=2\end{aligned}$ & $\begin{array}{c}24 \text { h UP } \geq 6 \\
=3\end{array}$ & \\
\hline CKD stage (X5) & $\mathrm{CKD} 1=0$ & $\mathrm{CKD} 2=1$ & $\mathrm{CKD} 3 \mathrm{a}=2$ & $\mathrm{CKD} 3 \mathrm{~b}=3$ & $\mathrm{CKD} 4=4$ \\
\hline BMI (X6) & $\mathrm{BMI}<18.5=0$ & $\begin{array}{c}18.5<\mathrm{BMI}< \\
25=1\end{array}$ & $\begin{array}{c}25<\mathrm{BMI}< \\
30=2\end{array}$ & $\mathrm{BMI} \geq 30=3$ & \\
\hline Hypoalbuminemia (X7) & $\mathrm{No}=0$ & Yes $=1$ & & & \\
\hline Hyperlipidemia (X8) & $\mathrm{No}=0$ & Yes $=1$ & & & \\
\hline Anemia (X9) & $\mathrm{No}=0$ & Yes $=1$ & & & \\
\hline Hyperuricemia (X10) & No $=0$ & Yes $=1$ & & & \\
\hline Hypertension (X11) & $\mathrm{No}=0$ & Yes $=1$ & & & \\
\hline $\begin{array}{l}\text { History of cardiovascular } \\
\text { diseases (X12) }\end{array}$ & $\mathrm{No}=0$ & Yes $=1$ & & & \\
\hline Malignant tumor (X13) & $\mathrm{No}=0$ & Yes $=1$ & & & \\
\hline $\begin{array}{l}\text { Urologic surgical procedures } \\
\text { (X14) }\end{array}$ & No $=0$ & Yes $=1$ & & & \\
\hline Smoking history (X15) & $\mathrm{No}=0$ & Yes $=1$ & & & \\
\hline $\begin{array}{l}\text { Frequency of alcohol use in past } \\
\text { year (X16) }\end{array}$ & Never $=0$ & Occasionally $=1$ & Frequently $=2$ & & \\
\hline C-reactive protein (X17) & $\begin{array}{c}\text { Interquartile of } \\
\text { CKD without } \\
\text { DM }=0\end{array}$ & $\begin{array}{l}\text { Interquartile } \\
\text { of CKD with } \\
\text { DM = } 1\end{array}$ & & & \\
\hline Total protein (X18) & $\begin{array}{c}\text { Mean value of } \\
\text { CKD without } \\
\text { DM }=0\end{array}$ & $\begin{array}{l}\text { Mean value } \\
\text { of CKD with } \\
\text { DM }=1\end{array}$ & & & \\
\hline Alkaline phosphatase (X19) & $\begin{array}{c}\text { Interquartile of } \\
\text { CKD without } \\
\text { DM }=0\end{array}$ & $\begin{array}{l}\text { Interquartile } \\
\text { of CKD with } \\
\text { DM = } 1\end{array}$ & & & \\
\hline
\end{tabular}

development of diabetic kidney disease in different patient populations [18, 24, 25].

Though anemia was more common in CKD patients with DM, fewer of these patients took anti-anemic drugs compared to CKD patients without DM. In addition, less than $50 \%$ of patients in either group were prescribed antilipemic, cardiovascular, cerebrovascular, or antianemic drugs. These drugs may therefore be underprescribed in CKD patients, perhaps contributing to complications and could delaying improvements in renal function. Finally, although $87.31 \%$ and $89.97 \%$ of patients were prescribed hypotensive drugs, some patients who were not receiving these treatments might have benefited from them.
Co-occurrence of CKD and DM does not always lead to the development of diabetic nephropathy. In this study, of the 99 CKD patients with DM who had undergone a renal biopsy, only 35 (35.4\%) had diabetic nephropathy; $62(60.6 \%)$ patients had non-diabetic renal disease (NDRD) and 2(2\%) had NDRD with diabetic nephropathy. In a previous study, $45.5 \%$ of biopsied type 2 DM patients were diagnosed with NDRD [26]. Another retrospective study in a southern Chinese population reported an NDRD diagnosis rate of 49\% (54/110) in CKD patients with type II DM [27]. The NDRD rate in other countries ranges between 10.0 and 93.5\% [27]. In the CKD patients without DM included in this study, IgAN $(20.2 \%)$ was the most common pathological type 
Table 3: Logistic regression analysis for factors associated with CKD with DM

\begin{tabular}{|c|c|c|c|c|}
\hline & \multicolumn{2}{|c|}{ Univariable analysis } & \multicolumn{2}{|c|}{ Multivariable analysis } \\
\hline & OR $(95 \%$ CI $)$ & $P$-value & OR $(95 \% \mathrm{CI})$ & $P$-value \\
\hline Female (vs. male) & $0.74(0.62-0.89)$ & NA & $0.86(0.66-1.12)$ & 0.26 \\
\hline \multicolumn{5}{|l|}{ Age group (years) } \\
\hline $18-44$ & Reference & & Reference & \\
\hline $45-59$ & $4.41(3.40-5.73)$ & NA & $3.59(2.71-4.77)$ & $<0.001^{*}$ \\
\hline$\geq 60$ & $8.57(6.59-11.15)$ & NA & $6.60(4.88-8.92)$ & $<0.001^{*}$ \\
\hline $\begin{array}{l}\text { Senior high school and above (vs. junior } \\
\text { high school and below) }\end{array}$ & $0.59(0.49-0.70)$ & $<0.001^{*}$ & $0.81(0.66-0.99)$ & $0.04^{*}$ \\
\hline \multicolumn{5}{|l|}{24 h UP $(g / 24$ h) } \\
\hline 24 h UP $<1$ & Reference & & Reference & \\
\hline $1<24$ h UP $<3.5$ & $1.42(1.16-1.75)$ & $<0.001^{*}$ & $1.37(1.08-1.74)$ & $0.01^{*}$ \\
\hline $3.5<24$ h UP $<6$ & $2.88(2.11-3.93)$ & $<0.001^{*}$ & $2.30(1.61-3.29)$ & $<0.001^{*}$ \\
\hline $24 \mathrm{~h} \mathrm{UP} \geq 6$ & $4.42(3.21-6.08)$ & $<0.001^{*}$ & $3.54(2.41-5.19)$ & $<0.001^{*}$ \\
\hline C-reactive protein $(\mathrm{mg} / \mathrm{L})$ & $1.03(0.97-1.10)$ & 0.33 & $0.92(0.86-1.00)$ & $0.04^{*}$ \\
\hline Total protein $(\mathrm{g} / \mathrm{L})$ & $0.993(0.989-0.996)$ & $<0.001^{*}$ & $0.997(0.993-1.002)$ & 0.23 \\
\hline Alkaline phosphatase (U/L) & $1.63(1.28-2.08)$ & $<0.001^{*}$ & $1.44(1.08-1.91)$ & $0.01^{*}$ \\
\hline \multicolumn{5}{|l|}{ CKD stage } \\
\hline CKD 1 & Reference & & Reference & \\
\hline CKD 2 & $1.30(0.81-2.09)$ & 0.28 & $1.02(0.62-1.67)$ & 0.95 \\
\hline CKD 3a & $3.40(2.18-5.31)$ & $<0.001^{*}$ & $2.26(1.39-3.66)$ & $0.001^{*}$ \\
\hline CKD $3 b$ & $3.78(2.52-5.67)$ & $<0.001^{*}$ & $1.99(1.25-3.16)$ & $0.004^{*}$ \\
\hline CKD 4 & $3.63(2.41-5.46)$ & $<0.001^{*}$ & $1.62(0.99-2.65)$ & 0.05 \\
\hline \multicolumn{5}{|l|}{ BMI $\left(\mathrm{kg} / \mathrm{m}^{2}\right)$} \\
\hline $\mathrm{BMI}<18.5$ & Reference & & Reference & \\
\hline $18.5 \leq \mathrm{BMI}<25$ & $2.34(1.08-5.10)$ & $0.03^{*}$ & $2.37(1.01-5.58)$ & $0.048^{*}$ \\
\hline $25 \leq \mathrm{BMI}<30$ & $4.08(1.89-8.80)$ & $<0.001^{*}$ & $3.85(1.62-9.14)$ & $0.002^{*}$ \\
\hline $\mathrm{BMI} \geq 30$ & $3.70(1.67-8.21)$ & $0.001^{*}$ & $4.19(1.73-10.15)$ & $0.002^{*}$ \\
\hline Hypoalbuminemia (yes vs. no) & $2.43(2.01-2.93)$ & $<0.001^{*}$ & $2.01(1.56-2.59)$ & $<0.001^{*}$ \\
\hline Hyperlipidemia (yes vs. no) & $1.32(1.09-1.61)$ & $0.005^{*}$ & $1.05(0.84-1.32)$ & 0.67 \\
\hline Anemia (yes vs. no) & $2.47(2.05-2.98)$ & $<0.001^{*}$ & $1.73(1.35-2.22)$ & $<0.001^{*}$ \\
\hline Hyperuricemia (yes vs. no) & $0.91(0.75-1.09)$ & 0.3 & $0.74(0.59-0.93)$ & $0.01^{*}$ \\
\hline Hypertension (yes vs. no) & $1.82(1.45-2.28)$ & $<0.001^{*}$ & $1.56(1.01-2.42)$ & $0.04^{*}$ \\
\hline $\begin{array}{l}\text { History of cardiovascular diseases (yes } \\
\text { vs. no) }\end{array}$ & $2.75(2.21-3.43)$ & $<0.001^{*}$ & $1.57(1.22-2.01)$ & $<0.001^{*}$ \\
\hline Malignant tumor (yes vs. no) & $0.86(0.37-1.99)$ & 0.73 & $1.22(0.48-3.09)$ & 0.68 \\
\hline $\begin{array}{l}\text { Urologic surgical procedures (yes vs. } \\
\text { no) }\end{array}$ & $0.86(0.55-1.33)$ & 0.49 & $1.04(0.63-1.70)$ & 0.88 \\
\hline Smoking history (yes vs. no) & $1.67(1.40-1.98)$ & $<0.001^{*}$ & $1.41(1.08-1.83)$ & $0.01^{*}$ \\
\hline \multicolumn{5}{|l|}{ Frequency of alcohol use in past year } \\
\hline Never & Reference & & Reference & \\
\hline Occasionally & $0.78(0.60-1.01)$ & 0.05 & $0.78(0.57-1.05)$ & 0.1 \\
\hline Frequently & $0.92(0.60-1.41)$ & 0.7 & $0.71(0.42-1.18)$ & 0.18 \\
\hline
\end{tabular}

${ }^{*} P<0.05$. BMI: Body Mass Index, CKD: Chronic Kidney Disease, 24 h UP: 24-hour Urinary Protein. 
Table 4: Pathological diagnoses of CKD patients with and without DM

\begin{tabular}{lcccc}
\hline Pathological diagnosis & $\begin{array}{c}(\mathbf{A}) \text { Case number } \\
(\boldsymbol{n}=\mathbf{9 9})\end{array}$ & $\begin{array}{c}\text { Percentage (\%) } \\
(\mathbf{B}) \text { Case number } \\
(\boldsymbol{n}=\mathbf{1 0 2 4})\end{array}$ & Percentage (\%) \\
\hline DN & 35 & 35.4 & 0 & 0 \\
IgAN & 20 & 20.2 & 501 & 48.93 \\
MN & 17 & 17.2 & 147 & 14.36 \\
MsPGN & 9 & 9.1 & 95 & 9.28 \\
DN+IgAN & 2 & 2 & 0 & 0 \\
Other types & 16 & 16.1 & 281 & 27.43 \\
\hline
\end{tabular}

$P<0.001$. A: CKD with DM group, B:CKD without DM group, DN: diabetic nephropathy, IgAN: IgA nephropathy, MN: membranous nephropathy, MsPGN: mesangial proliferative glomerulonephritis, DN + IgAN: diabetic nephropathy with IgA nephropathy.

in NDRD patients, followed by MN (19.2\%). Similar findings were reported in another study of NDRD patients, in which the most prevalent pathologic types were IgAN $(43.5 \%)$ and $\mathrm{MN}(14.5 \%)$ [28]. At Xiangya Hospital, 34\% of NDRD patients exhibited IgAN; MN was the second most common type (22\%) [26]. However, some studies report slightly different results. For example, MN was the most commonly-observed type (26.2\%), followed closely by $\operatorname{IgAN}(24.6 \%)$, in one report [27].

In general, NDRD is relatively common in CKD patients with $\mathrm{DM}$, and renal biopsies are therefore crucial for correctly diagnosing and monitoring renal diseases. However, out of the 635 Chinese CKD patients with DM included in this study, only99 (18.38\%) had undergone a renal biopsy. Clinicians in China should perform renal biopsies more often to help identify etiologies of CKD more effectively, thus avoiding misdiagnosis and mistreatment. The results of this cross-sectional study should be explored further in prospective studies of CKD patient populations.

\section{MATERIALS AND METHODS}

\section{Study participants}

3499 pre-dialysis CKD patients between the ages of 18 and 74 were enrolled in the C-STRIDE cohort between November 2011 and April 2016. C-STRIDE is a multicenter cohort of Chinese CKD patients from 39 clinical centers located in 28 cities in 22 provinces of China. Briefly, patients within the age range with specific estimated glomerular filtration rates (eGFR) were included, regardless of etiology. Severe heart failure, systemic inflammatory illness, autoimmune disease, and some other factors served as exclusion criteria; C-STRIDE criteria have been described in detail previously [7]. C-STRIDE patients with DM identified based on the World Health Organization (1998) definition [29] were included in the CKD with DM group, while CKD patients without DM were included in the CKD without DM group.

The study was approved by the ethics committees of all 39 centers involved and was conducted in accordance with the principles contained within the Declaration of Helsinki. All participants gave written informed consent before data collection.

\section{Data collection}

Data were collected on demographic information, clinical characteristics, laboratory examinations, complications, and concomitant medication. Renal biopsy reports were collected for enrolled patients who had undergone a renal biopsy. Demographic and clinical information and laboratory examinations included gender, age, education level, body mass index (BMI), systolic blood pressure, diastolic blood pressure, eGFR (using the Chronic Kidney Disease Epidemiology Collaboration creatinine equation), smoking and drinking history, and $24 \mathrm{~h}$ urine albumin.

\section{Variable definition}

Hypertension was defined by systolic blood pressure $\geq 140 \mathrm{mmHg}$, diastolic blood pressure $\geq 90 \mathrm{mmHg}$, and/ or use of antihypertensive drugs within the past 2 weeks. Hyperlipidemia was defined by total cholesterol $\geq 6.22$ $\mathrm{mM}$, triglycerides $\geq 2.26 \mathrm{mM}$, high-density lipoprotein $<1.04 \mathrm{mM}$, and/or use of antilipemic drugs within the past 2 weeks. Anemia was defined by hemoglobin $<120 \mathrm{~g} / \mathrm{L}$ for males and $<110 \mathrm{~g} / \mathrm{L}$ for females and/or use of erythropoietin, chalybeate, or another anti-anemic treatment within the past 2 weeks. Hypoalbuminemia was defined by plasma albumin $<30 \mathrm{~g} / \mathrm{L}$ or vascular diseases, including cardiovascular disease, cerebrovascular disease, and peripheral angiopathies. Antihypertensive, antilipemic, anti-anemic, and vascular disease drugs were considered when collecting information on drug use. Frequency of alcohol use over the past year was scored as follows: "Occasionally" indicates use 1-3 times/month and 1-2 times/week; "Frequently" indicates 3-5 times/week, almost once/day, and more than once/day. Angiotensin-converting enzyme inhibitors, angiotensin receptor blockers, calcium antagonists, diuretic hydragogue, $\alpha$-acceptor blocker, $\beta$-acceptor blocker, 
$\alpha \beta$-acceptor blocker, and centrally-acting antihypertensive treatments were considered hypotensive drugs. Statins and fibrates were considered antilipemic drugs. Ferralia, folacin, and erythropoietin were considered antianemic drugs. Antiplatelet and anticoagulant drugs were considered vascular drugs.

\section{Statistical analyses}

Continuous variables are presented as means $\pm \mathrm{SD}$ or as medians with interquartile ranges, as appropriate. $T$-tests or Mann-Whitney nonparametric tests were used for comparisons between groups. Categorical variables are presented as frequencies and percentages and were compared using chi square tests.

To mitigate the effects of missing data, we performed multiple imputation for missing data values using a fully conditional specification method in SAS. For each patient with missing data, all available data values were included as predictors in the imputation procedure for the prediction of missing data values; the original scale or categories were used before being further categorized in the regression analysis. We used a regression method to impute missing values for continuous variables that were normally distributed, a predictive mean matching method for continuous variables that were not normally distributed, and a logistic regression method for categorical variables of a binary or ordinal nature. Five imputed data sets were generated and analyzed separately, and the results obtained from the separate complete data sets were then combined.

We analyzed associations between demographic, clinical, and laboratory data from the CKD with DM group and the relevant covariates using logistic regression models. Independent variables were screened first by using variables identified in previous studies that might be closely related to $\mathrm{CKD}$ with DM as independent variables in the regression analysis. The independent variables were then screened based on experts' clinical and research experience. Univariable and multivariable adjusted odds ratios (ORs) with 95\% CIs are reported. The following covariates were included in the multivariable logistic regression models: age, sex, education completed, $24 \mathrm{~h}$ urinary protein, $\mathrm{C}$-reactive protein, total protein, alkaline phosphatase, CKD stage 1-4, BMI, hypoalbuminemia (yes vs. no), anemia (yes vs. no), hypertension (yes vs. no), hyperlipidemia (yes vs. no), hyperuricemia (yes vs. no), vascular disease history (yes vs. no), malignant tumor (yes vs. no), urologic surgical procedures (yes vs. no), smoking (yes vs. no), and alcohol use.

Multivariable logistic regression analysis was used to identify factors related to CKD with DM. Results from regression analysis are presented as odds ratios with $95 \%$ confidence intervals. $P$-values $<0.05$ were considered statistically significant. SAS statistical software (ver. 9.4; SAS Institute, CA, USA) was used for statistical analyses.

\section{Author contributions}

ZSL, JJZ, MHZ, and LXZ conceived of and designed the study. LY, HDZ, and YJL searched databases and checked results against inclusion and exclusion criteria. JWW analyzed the data. JJZ and LY wrote the initial draft of the manuscript. JWH contributed to manuscript preparation. JJZ reviewed and edited the manuscript. All authors read and approved the final manuscript.

\section{ACKNOWLEDGMENTS}

The authors thank all the patients who participated in the C-STRIDE cohort. The authors would also like to acknowledge the National Key Technology R\&D Program of the Ministry of Science and Technology and the Beijing Science and Technology Committee for their support.

\section{CONFLICTS OF INTEREST}

The authors declare that they have no conflicts of interest.

\section{FUNDING}

This study was supported by the National Key Technology R\&D Program of the Ministry of Science and Technology (Project No.2011BAI10B01), the Beijing Science and Technology Committee (Project No. D131100004713007; "Establishment of early diagnosis pathway and model for evaluating progression of chronic kidney disease"), the Science and Technology Huimin Project of Henan Province (Project No. 162207310001), and the National Science and Technology Support Program (Project No. 2015BAI12B05; Popularization and application of clinical research on chronic kidney disease).

\section{REFERENCES}

1. Federation ID. IDF Diabetes Atlas · Seventh Edition. 2016.

2. Zimmet P, Alberti KG, Shaw J. Global and societal implications of the diabetes epidemic. Nature. 2001; 414:782-7.

3. Danaei G, Finucane MM, Lu Y, Singh GM, Cowan MJ, Paciorek CJ, Lin JK, Farzadfar F, Khang YH, Stevens GA, Rao M, Ali MK, Riley LM, et al. National, regional, and global trends in fasting plasma glucose and diabetes prevalence since 1980: systematic analysis of health examination surveys and epidemiological studies with 370 country-years and 2.7 million participants. Lancet. 2011; 378:31-40.

4. Lin B, Shao L, Luo Q, Ou-yang L, Zhou F, Du B, He Q, $\mathrm{Wu}$ J, Xu N, Chen J. Prevalence of chronic kidney disease 
and its association with metabolic diseases: a cross-sectional survey in Zhejiang province, Eastern China. BMC Nephrol. 2014; 15:36

5. Zhang L, Long J, Jiang W, Shi Y, He X, Zhou Z, Li Y, Yeung RO, Wang J, Matsushita K, Coresh J, Zhao MH, Wang H, et al. Trends in Chronic Kidney Disease in China. N Engl J Med. 2016; 375:905-6.

6. Xu Y, Wang L, He J, Bi Y, Li M, Wang T, Wang L, Jiang Y, Dai M, Lu J, Xu M, Li Y. Prevalence and control of diabetes in Chinese adults. JAMA. 2013; 310:948-59.

7. Gao B, Zhang L, Wang H, Zhao M. Chinese cohort study of chronic kidney disease: design and methods. Chin Med J. 2014; 127:2180-5.

8. Gosmanov AR, Wall BM, Gosmanova EO. Diagnosis and treatment of diabetic kidney disease. Am J Med Sci. 2014; 347:406-13.

9. Goldhaber A, Ness-Abramof R, Ellis MH. Prevalence of anemia among unselected adults with diabetes mellitus and normal serum creatinine levels. Endocr Pract. 2009; 15:714-9.

10. Grossman C, Dovrish Z, Koren-Morag N, Bornstein G, Leibowitz A. Diabetes mellitus with normal renal function is associated with anaemia. Diabetes Metab Res Rev. 2014; 30:291-6.

11. Bulum T, Prkacin I, Blaslov K, Zibar K, Duvnjak L. Association between red blood cell count and renal function exist in type 1 diabetic patients in the absence of nephropathy. Coll Antropol. 2013; 37:777-82.

12. Thomas M, Tsalamandris C, MacIsaac R, Jerums G. Anaemia in diabetes: an emerging complication of microvascular disease. Curr Diabetes Rev. 2005; 1:107-26.

13. Thomas MC, MacIsaac RJ, Tsalamandris C, Molyneaux L, Goubina I, Fulcher G, Yue D, Jerums G. The burden of anaemia in type 2 diabetes and the role of nephropathy: a cross-sectional audit. Nephrol Dial Transplant. 2004; 19:1792-7.

14. Thomas MC, MacIsaac RJ, Tsalamandris C, Power D, Jerums G. Unrecognized anemia in patients with diabetes: a cross-sectional survey. Diabetes Care. 2003; 26:1164-9.

15. Pappa M, Dounousi E, Duni A, Katopodis K. Less known pathophysiological mechanisms of anemia in patients with diabetic nephropathy. Int Urol Nephrol. 2015; 1365-72.

16. Thomas MC, MacIsaac RJ, Tsalamandris C, Molyneaux L, Goubina I, Fulcher G, Yue D, Jerums G. Anemia in patients with type 1 diabetes. J Clin Endocrinol Metab. 2004; 89:4359-63.

17. Chen SC, Tseng CH. Dyslipidemia, kidney disease, and cardiovascular disease in diabetic patients. Rev Diabet Stud. 2013; 10:88-100.

18. Lorenzo V, Saracho R, Zamora J, Rufino M, Torres A. Similar renal decline in diabetic and non-diabetic patients with comparable levels of albuminuria. Nephrol Dial Transplant. 2010; 25:835-41.

19. Ito H, Mifune M, Abe M, Oshikiri K, Antoku S, Takeuchi Y, Togane M, Ando S, Tsugami E. Hypertension resistant to antihypertensive agents commonly occurs with the progression of diabetic nephropathy in Japanese patients with type 2 diabetes mellitus: a prospective observational study. BMC Nephrol. 2012; 13:48.

20. Zhou JH, Chen XM, Xie YS, Li JJ, Wu J, Cai GY. [Comparison between diabetic nephropathy and non-diabetic renal diseases and establishment of diagnostic formula] [Article in Chinese]. Chin J Nephrol. 2005; 21:182-5.

21. Liang S, Zhang XG, Cai GY, Zhu HY, Zhou JH, Wu J, Chen P, Lin SP, Qiu Q, Chen XM. Identifying parameters to distinguish non-diabetic renal diseases from diabetic nephropathy in patients with type 2 diabetes mellitus: a meta-analysis. PLoS One. 2013; 8:e64184.

22. Grandfils N, Detournay B, Attali C, Joly D, Simon D, Vergès $\mathrm{B}$, Toussi $\mathrm{M}$, Briand $\mathrm{Y}$, Delaitre O. Glucose lowering therapeutic strategies for type 2 diabetic patients with chronic kidney disease in primary care setting in france: a cross-sectional study. Int J Endocrinol. 2013; 2013:640632.

23. Foley RN, Murray AM, Li S, Herzog CA, McBean AM, Eggers PW, Collins AJ. Chronic kidney disease and the risk for cardiovascular disease, renal replacement, and death in the United States Medicare population, 1998 to 1999. J Am Soc Nephrol. 2005; 16:489-95.

24. Onyenwenyi C, Ricardo AC. Impact of Lifestyle Modification on Diabetic Kidney Disease. Curr Diab Rep. 2015; 15:60.

25. Nordén G, Nyberg G. Smoking and diabetic nephropathy. Acta Med Scand. 1984; 257-61.

26. Bi H, Chen N, Ling G, Yuan S, Huang G, Liu R. Nondiabetic renal disease in type 2 diabetic patients: a review of our experience in 220 cases. Ren Fail. 2011; 33:26-30.

27. Si MJ, Ye ZC, Zhao WB, Zhang XH, Li Y, Liu X, Peng H, Lou TQ. [Renal pathology and clinical features of patients with type 2 diabetes mellitus and chronic kidney disease.] [Article in Chinese]. Chin J Nephrol. 2016; 32:401-5.

28. Byun JM, Lee CH, Lee SR, Moon JY, Lee SH, Lee TW, Ihm CG, Jeong KH. Renal outcomes and clinical course of nondiabetic renal diseases in patients with type 2 diabetes. Korean J Intern Med. 2013; 28:565-72.

29. Alberti KG, Zimmet PZ. Definition, diagnosis and classification of diabetes mellitus and its complications. Part 1: diagnosis and classification of diabetes mellitus provisional report of a WHO consultation. Diabet Med. 1998; 15:539-53. 